\title{
Depth Electrodes in Pediatric Epilepsy Surgery
}

\author{
Janani Kassiri, Jeff Pugh, Sharon Carline, Laura Jurasek, Thomas Snyder, \\ Matt Wheatley, D. Barry Sinclair
}

\begin{abstract}
Background: The surgical removal of the epileptogenic zone in medically intractable seizures depends on accurate localization to minimize the neurological sequelae and prevent future seizures. To date, few studies have demonstrated the use of depth electrodes in a pediatric epilepsy population. Here, we report our study of pediatric epilepsy patients at our epilepsy center who were successfully operated for medically intractable seizures following the use of intracranial depth electrodes. In addition, we detail three individuals with distinct clinical scenarios in which depth electrodes were helpful and describe our technical approach to implantation and surgery. Methods: We retrospectively reviewed 18 pediatric epilepsy patients requiring depth electrode studies who presented at the University of Alberta Comprehensive Epilepsy Program between 1999 and 2010 with medically intractable epilepsy. Patients underwent cortical resection following depth electrode placement according to the Comprehensive Epilepsy Program surgical protocols after failure of surface electroencephalogram and magnetic resonance imaging to localize ictal onset zone. Result: The ictal onset zone was successfully identified in all 18 patients. Treatment of all surgical patients resulted in successful seizure freedom (Engel class I) without neurological complications. Conclusion: Intracranial depth electrode use is safe and able to provide sufficient information for the identification of the epileptogenic zone in pediatric epilepsy patients previously not considered for epilepsy surgery.
\end{abstract}

RÉSUMÉ: Électrodes profondes dans la chirurgie de l'épilepsie en pédiatrie. Contexte : L'ablation chirurgicale de la zone épileptogène chez les patients atteints de crises d'épilepsie réfractaires au traitement médical dépend d'une localisation précise du foyer épileptogène afin de minimiser les séquelles neurologiques et de prévenir les crises. À ce jour, peu d'études ont démontré l'utilité d'électrodes profondes chez une population pédiatrique atteinte d'épilepsie. Notre étude porte sur des patients d'âge pédiatrique atteints d'épilepsie réfractaire au traitement médical, opérés avec succès après implantation d'électrodes profondes dans notre centre de traitement de l'épilepsie. De plus, nous décrivons en détail trois patients présentant des scénarios cliniques distincts chez qui des électrodes profondes ont été utiles et nous décrivons notre approche technique d'implantation de ces électrodes et de la chirurgie. Méthode : Nous avons révisé rétrospectivement les dossiers de 18 enfants atteints d'épilepsie nécessitant des études au moyen d'électrodes profondes pour une épilepsie réfractaire au traitement médical dans le cadre du University of Alberta Comprehensive Epilepsy Program entre 1999 et 2010. Les patients ont subi une résection corticale après implantation d'électrodes profondes effectuée selon les protocoles chirurgicaux du Comprehensive Epilepsy Program parce que l'électroencéphalogramme de surface et l'imagerie par résonance magnétique n'aient pas pu localiser la zone épileptogène. Résultats : La zone épileptogène a été identifiée avec succès chez ces 18 patients. Le traitement chirurgical de tous ces patients a entraîné une absence complète de crises (Classe I de Engal) sans complication neurologique. Conclusion : L'utilisation d'électrodes intracrâniennes profondes est sûre et fournit des informations suffisantes pour l'identification de la zone épileptogène chez les patients d'âge pédiatrique atteints d'épilepsie chez qui un traitement chirurgical n'était pas envisagé dans le passé.

Can J Neurol Sci. 2013; 40: 48-55

Epilepsy surgery has become a treatment option for children with medically intractable epilepsy ${ }^{1-6}$. Accurate localization and removal of the epileptogenic zone is crucial in order to achieve seizure control. Most centers like ours reserve intracranial recording for complex cases, such as those with potential multiple foci or dual pathology, or to resolve discordant data in which surface electroencephalogram (EEG) and magnetic resonance imaging (MRI) do not provide enough information to correctly recognize the ictal onset zone.

The goal of the surgery is to accurately identify and remove the epileptogenic zone while minimizing new functional deficits from surgery. Our main objective though remains the attainment of complete seizure freedom without harm to the patient.

Intracranial recording includes epidural pegs, subdural grid placement, and depth electrode insertion. In the past, like most pediatric epilepsy centers we have implanted large subdural grids in patients with epilepsy in order to further map the epileptic zone. We have encountered several complications with subdural grids including infection, hemorrhage, aseptic meningitis and eventual shift in grid placement resulting in complications and inaccurate information from the intracranial recordings. Several years ago, we moved to stereotactically placed intracranial depth electrodes in both adult and pediatric cases in order to avoid these complications of invasive subdural monitoring.

From the Comprehensive Epilepsy Program, University of Alberta Hospital, Edmonton, Alberta, Canada.

Received February 3, 2012. Final Revisions Submitted July 23, 2012. Correspondence to: D Barry Sinclair, Comprehensive Epilepsy Program, University of Alberta, 11402 University Avenue, Edmonton, Alberta, T6G 2J3, Canada. Email: Barry.Sinclair@albertahealthservices.ca. 
Previous studies have shown that deep brain structures are more efficiently monitored with depth electrodes ${ }^{7,8}$. Here, we report our experience with pediatric epilepsy patients treated with depth electrodes and report their outcomes. In addition, we describe three individuals with distinct clinical scenarios who exemplify the complex types of patients in whom depth electrodes can be helpful and detail our approach to surgery.

\section{METHODS}

We reviewed the medical records of 18 depth electrode patients (ten males and 8 females; ages 3-18 years) seen in our Comprehensive Epilepsy Program at the University of Alberta hospital between 1999-2010. Medical records were systematically evaluated for seizure history, neurologic examination, EEG, long-term video-electroencephalography (LTVEEG, Nicolet) monitoring, magnetic resonance imaging (MRI; Siemens 1.5 Tesla), neuropsychological assessment (Dr. T. Snyder), and depth electrode insertion, surgery, pathology, and post-operative outcomes.

\section{Pre-surgical evaluation}

All children experienced intractable seizures with failure of multiple medications and presented with unclear scalp EEG results or discordant preoperative data. Initially, all children admitted to the Pediatric Epilepsy Monitoring Unit were evaluated with multiple scalp EEG, LTVEEG, MRI, and neuropsychological evaluations. Depth electrode insertion was undertaken following a discussion at seizure conference because of lack of consistent concordance of data for the localization of epileptogenic foci using all of the above techniques.

Placement was determined by clinical seizure semiology, surface EEG, and MRI. For each patient a hypothesis was formulated, i.e. seizures are either from the right temporal or right frontal lobe, which could be answered by stereotactically placed depth electrodes.

\section{Depth electrode placement}

The neurologist and neurosurgeon met preoperatively to decide on the placement of the depth electrodes. This is based on seizure semiology, surface EEG, MRI and the hypothesis as to origin of seizures generated at seizure conference. The individual electrode trajectories are then planned and plotted using the neuronavigation system (Medtronics, Stealth). At the time of the operation the frameless stereotactic arm ("Olivier arm", Hybex Industries) is used to align the depth electrode (DIXI medical) along the preoperatively planned trajectory. A two mm twist drill hole is made for each electrode insertion, and the electrode is passed down to the target. The electrodes are fixed in place using a guide screw and cap (DIXI medical) and a head dressing is applied. There is a $7 \mathrm{~mm}$ distance between each electrode and the number of electrodes is variable (between 416) per patient. Please see Figure 1 for sample illustration. The boundary for surgical resection was defined by a $5 \mathrm{~mm}$ resection in all directions around the active zone identified pre operatively by the depth electrodes. Electrocorticography was not performed as it did not, in our experience, add any additional information about the epileptic zone.

\section{Post-surgical outcome}

Patients were assessed for complications, seizure frequency as well as neurological and cognitive outcome immediately and postoperatively, at three months, six months, and at one year follow up by our Comprehensive Epilepsy team. Each patient had a seizure diary, EEG and a neurological and neuropsychological exam. The patients were then seen annually in our epilepsy clinic (duration of one to ten years, mean of three years).

Seizure outcome is classified according to Engel's classification $^{9}$ into four main outcome categories based on the patient's last postoperative seizure status. Patients who were seizure free or had only auras since surgery were assigned to

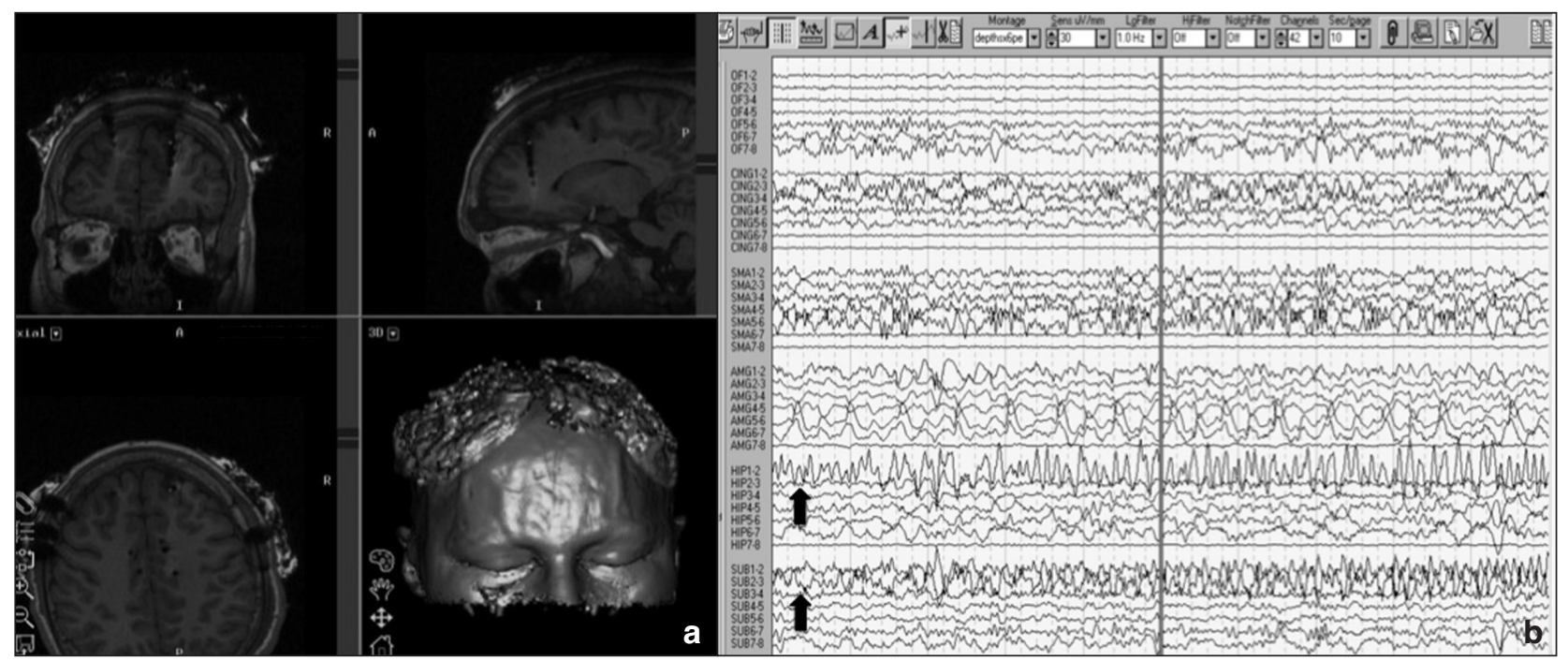

Figure 1: (Patient \#2): Frontal vs Temporal seizures. a) Magnetic resonance imaging showing implanted frontal and temporal depth electrodes. b) Depth electrode electroencephalogram showing seizure origin (arrows) in right amygdala and hippocampus. 
Table: Characteristics of patients with depth electrodes

\begin{tabular}{|c|c|c|c|c|c|c|c|c|c|c|}
\hline Subject & Gender & $\begin{array}{l}\text { Age at seizure } \\
\text { onset }\end{array}$ & $\begin{array}{l}\text { Age at } \\
\text { surgery }\end{array}$ & MRI & $\begin{array}{c}\text { EEG } \\
\text { discharges }\end{array}$ & $\begin{array}{c}\text { Depth } \\
\text { electrode } \\
\text { Discharges }\end{array}$ & Surgery & $\begin{array}{l}\text { Engel } \\
\text { class }\end{array}$ & Complications & Pathology \\
\hline 1 & $\mathrm{M}$ & $15 \mathrm{Y}$ & $17 \mathrm{Y}$ & $\mathrm{N}$ & $\begin{array}{l}\mathrm{L} \text { temporal } \\
\text { and frontal }\end{array}$ & Bifrontal & $\begin{array}{l}\mathrm{L} \text { orbito-frontal } \\
\text { resection }\end{array}$ & 1 & No & FCD \\
\hline 2 & $\mathrm{M}$ & $8 \mathrm{Y}$ & $15 \mathrm{Y}$ & $\begin{array}{c}\mathrm{L} \\
\text { subependymal } \\
\text { cyst }\end{array}$ & $\begin{array}{l}\mathrm{R} \text { fronto } \\
\text { temporal }\end{array}$ & $\begin{array}{l}\mathrm{R} \text { fronto- } \\
\text { temporal }\end{array}$ & $\begin{array}{c}\mathrm{R} \text { anterior temporal } \\
\text { lobectomy }\end{array}$ & $\begin{array}{c}1 \\
\text { (Aura) }\end{array}$ & No & Gliosis \\
\hline 3 & $\mathrm{M}$ & $4 \mathrm{Y}$ & $13 \mathrm{Y}$ & $\mathrm{N}$ & $\begin{array}{l}\text { L occipital } \\
\text { and frontal }\end{array}$ & $\begin{array}{l}\text { Bilateral } \\
\text { occipito- } \\
\text { temporal }\end{array}$ & L occipital resection & 1 & No & FCD \\
\hline 4 & $\mathrm{M}$ & $2 \mathrm{Y}$ & $15 \mathrm{Y}$ & $\mathrm{N}$ & $\begin{array}{l}\text { L frontal } \\
\text { temporal }\end{array}$ & $\mathrm{L}$ frontal & $\begin{array}{l}\mathrm{L} \text { frontal insular } \\
\text { resection }\end{array}$ & 1 & No & Gliosis \\
\hline 5 & $\mathrm{M}$ & $3 \mathrm{MO}$ & $16 \mathrm{Y}$ & $\begin{array}{c}\text { L cerebellar } \\
\text { pontine angle } \\
\text { tumor }\end{array}$ & Bifrontal & Bifrontal & $\begin{array}{l}\text { Not a surgical } \\
\text { candidate }\end{array}$ & $\mathrm{N} / \mathrm{A}$ & N/A & $\mathrm{N} / \mathrm{A}$ \\
\hline 6 & $\mathrm{M}$ & $3 \mathrm{MO}$ & $5 \mathrm{Y}$ & $\begin{array}{l}\text { Multiple } \\
\text { tubers }\end{array}$ & $\begin{array}{c}\mathrm{L} \\
\text { hemisphere }\end{array}$ & $\begin{array}{l}\text { Bifronto- } \\
\text { temporal }\end{array}$ & $\begin{array}{c}\mathrm{L} \text { frontal } \\
\text { lesionectomy }\end{array}$ & 1 & No & Tuber \\
\hline 7 & $\mathrm{~F}$ & $2.5 \mathrm{Y}$ & $17 \mathrm{Y}$ & $\mathrm{N}$ & Bifrontal & $\begin{array}{l}\text { Bifrontal } \\
\text { and L } \\
\text { temporal }\end{array}$ & $\begin{array}{l}\mathrm{L} \text { anterior temporal } \\
\text { resection }\end{array}$ & 1 & No & Gliosis \\
\hline 8 & $\mathrm{M}$ & $10 \mathrm{Y}$ & $15 \mathrm{Y}$ & $\mathrm{N}$ & $\mathrm{R}$ frontal & Bifrontal & $\mathrm{R}$ frontal resection & 1 & No & $\mathrm{N}$ \\
\hline 9 & $\mathrm{~F}$ & $3.5 \mathrm{Y}$ & $13 \mathrm{Y}$ & $\begin{array}{l}\text { L occipital } \\
\text { FCD }\end{array}$ & $\begin{array}{c}\mathrm{L}, \mathrm{R} \\
\text { occipital }\end{array}$ & $\begin{array}{l}\text { Bioccipital } \\
\text { and } \\
\text { bitemporal }\end{array}$ & Awaiting surgery & N/A & N/A & N/A \\
\hline 10 & $\mathrm{~F}$ & $10 \mathrm{Y}$ & $17 \mathrm{Y}$ & $\mathrm{N}$ & L occipital & L occipital & L occipital resection & 1 & No & FCD \\
\hline 11 & $\mathrm{~F}$ & $3 \mathrm{Y}$ & $16 \mathrm{Y}$ & Bifrontal FCD & $\begin{array}{l}\text { Right } \\
\text { frontal }\end{array}$ & Bifrontal & $\begin{array}{c}\mathrm{R} \text { frontal } \\
\text { lesionectomy }\end{array}$ & 1 & No & FCD \\
\hline 12 & $\mathrm{~F}$ & $5 \mathrm{Y}$ & $17 \mathrm{Y}$ & Bilateral MTS & R temporal & $\begin{array}{l}\text { Bilateral } \\
\text { temporal }\end{array}$ & $\begin{array}{c}\mathrm{R} \text { amygdalo } \\
\text { hippocampectomy }\end{array}$ & 1 & No & MTS \\
\hline 13 & $\mathrm{M}$ & $6 \mathrm{Y}$ & $18 \mathrm{Y}$ & $\mathrm{N}$ & $\mathrm{N}$ & $\begin{array}{l}\text { Bifrontal } \\
\text { and bi } \\
\text { temporal }\end{array}$ & Left SMA resection & 1 & No & FCD \\
\hline 14 & M & $5 \mathrm{Y}$ & $11 \mathrm{Y}$ & $\mathrm{N}$ & Generalized & Bitemporal & $\begin{array}{c}\mathrm{R} \text { mesial temporal } \\
\text { resection }\end{array}$ & 1 & No & MTS \\
\hline 15 & $\mathrm{~F}$ & $6 \mathrm{Y}$ & $13 \mathrm{Y}$ & $\begin{array}{c}\text { L focal gliosis } \\
\text { temporal and } \\
\text { R frontal }\end{array}$ & Bifrontal & $\begin{array}{c}\text { Bifronto- } \\
\text { parietal }\end{array}$ & $\begin{array}{c}\mathrm{L} \text { frontal } \\
\text { lesionectomy }\end{array}$ & 1 & No & Gliosis \\
\hline 16 & $\mathrm{~F}$ & $10 \mathrm{Y}$ & $14 \mathrm{Y}$ & $\begin{array}{l}\text { L occipital } \\
\text { gliosis }\end{array}$ & L occipital & $\begin{array}{l}\text { L parieto- } \\
\text { occipital }\end{array}$ & Awaiting surgery & N/A & N/A & $\mathrm{N} / \mathrm{A}$ \\
\hline 17 & $\mathrm{M}$ & $4 \mathrm{Y}$ & $13 \mathrm{Y}$ & $\begin{array}{l}\text { R amygdala } \\
\text { FCD }\end{array}$ & $\begin{array}{l}\mathrm{R} \text { and } \mathrm{L} \\
\text { temporal }\end{array}$ & Bitemporal & $\begin{array}{c}\mathrm{R} \text { anterior temporal } \\
\text { lesionectomy }\end{array}$ & 1 & NPE & Gliosis \\
\hline 18 & $\mathrm{~F}$ & $2 \mathrm{Y}$ & $3 Y$ & $\mathrm{~L}$ frontal FCD & Bifrontal & $\mathrm{L}$ frontal & $\begin{array}{c}\mathrm{L} \text { frontal } \\
\text { lesionectomy }\end{array}$ & 1 & No & FCD \\
\hline
\end{tabular}

N, normal; F, female; M, male; Y, years; MO, months; L, left; R, right; FCD, focal cortical dysplasia; MTS, mesial temporal sclerosis; NPE, neurogenic pulmonary edema; N/A, not applicable.

Class I; those patients who experienced rare seizures postoperative (two or more per year) were assigned to Class II; patients with a seizure reduction $>75 \%$ were classified in Class III; and patients who experienced $\leq 75 \%$ reduction in seizure frequency were assigned to Class IV.

\section{RESULTS}

The demographic and clinical features of the 18 patients included in this study are described in the Table. The mean patient age was 14.1 years, with a range of 3 to 18 years. Ten patients were male and eight were female. The mean period of
LVEEG monitoring was 7.5 days with a range of 1-17 days. All patients underwent preoperative neuropsychological testing and MRI. Eight patients had a normal MRI. Four patients were found to have a focal cortical dysplasia (one bifrontal, one left occipital, one left frontal, and one right temporal); one had multiple cortical tubers; two had gliosis (one left temporal as well as right frontal and one left occipital); one had bilateral mesial temporal sclerosis, while two had incidental findings (one a left subependymal cyst and one a cerebellopontine angle tumor) with otherwise normal cortical MRI. 
The location and number of depth electrode placement varied depending on the individual case based on seizure semiology, surface EEG, and MRI. Of the 18 patients with depth electrodes five had unilateral (one right frontal, two left frontal, one left occipital, one left parieto-occipital) depth electrode placements and 13 had bilateral (four bifrontal, three bitemporal, two bioccipito-temporal, three bifronto-temporal, one bifrontoparietal) placements.

On the basis of data obtained from seizure semiology, depth EEG monitoring, and MRI a cortical resection was performed in 15 of 18 patients. One patient (\#5) had bifrontal onset so that we did not proceed with surgery; another two patients (\#9,\#16) are awaiting surgery. The resection involved the frontal lobe in eight patients (six left, two right), of the temporal lobe in five (three right and one left anterior temporal as well as one mesial temporal), and of the left occipital lobe in two patients.

Seizure outcomes are described in Table 1 . Of the 15 patients who underwent resection, the outcome currently is Engel Class I in all. One patient developed acute neurogenic pulmonary edema following bitemporal depth electrode placement and later underwent a right anterior temporal lobe lesionectomy and has been previously described in the literature and has been seizure free $^{10}$. Histopathological examination revealed mesial temporal sclerosis in two cases, focal cortical dysplasia in six cases, a tuber (of tuberous sclerosis) in one case, and gliosis in five cases. One case did not show any tissue abnormality.

\section{Case Presentations}

Examples of three different cases, where implanted depth electrodes were helpful, are presented below to demonstrate usefulness of depth electrodes in specific clinical scenarios.

\section{Case 1 (Patient \#2): Frontal vs. Temporal lobe}

Patient \#2 was a 16-year-old, right-handed male with a history of complex partial seizures starting at the age of eight.

He was the product of a normal pregnancy and had no history of central nervous system (CNS) infection, trauma, or developmental delay. Neurological exam and cognition was normal. The family history was deemed to be non-contributory.

Starting at the age of eight years, the patient reported experiencing unusual episodes of "funny feelings" in both legs, which sometimes were more prominent in the left leg. These episodes were followed by falling down, whole body stiffening, and kicking. The events lasted for approximately 30 seconds and predominately occurred at night with left sided post-ictal weakness. A diagnosis of Frontal Lobe Epilepsy was made.

In the Pediatric Epilepsy Monitoring Unit, LTVEEG recordings showed right frontal lobe epileptic discharges, and MRI showed a small arachnoid cyst in the left anterior temporal lobe, which was considered an incidental finding. The patient was treated with carbamazepine but continued to have seizures. It was unclear if the seizures were of frontal or anterior temporal origin based on surface EEG recordings.

Subsequently, depth electrodes were implanted in both temporal and frontal regions (Figure 1a). All of the patient's seizures were determined to have originated in the right temporal lobe, from the hippocampus and amygdala and spread to right frontal region (Figure 1b). As a result of this finding, the patient underwent epileptic surgery with a right anterior temporal lobectomy. He has been seizure free for the past five years.

\section{Case 2 (Patient \#12): Bitemporal depth electrode}

The patient was a 17 year-old right handed female with history of complex partial seizures since the age of 18 months.

She was the product of a normal pregnancy and full term delivery. The patient met all normal milestones on time. There was a prolonged febrile seizure experienced at 18 months-ofage, which resulted in admission to the pediatric intensive care unit (PICU). The patient also had a history of migraine headaches and attention deficit disorder (ADD).

The seizures began at five years-of-age. The patient experienced an aura followed by a "funny smell" and a feeling of fear. This was normally followed by flushing of the skin, staring, and progressed to unresponsiveness. The seizures would last approximately 30-120 seconds, and would cluster. Clusters occurred every two weeks. The seizures were initially controlled with carbamazepine.

Over time the seizure frequency increased to the point of daily occurrence. At the time, the patient was admitted to The Pediatric Epilepsy Monitoring Unit (PEMU) and seizures with surface EEG were recorded from the left temporal lobe; an MRI revealed left Mesial Temporal Sclerosis (MTS). The patient was treated with escalating doses of carbamazepine.

Three years later, surface EEG revealed focal epileptic discharges from the right temporal lobe and the patient was readmitted to the PEMU for additional testing. Results now showed that complex partial seizures were occurring independently, arising from both left and right temporal lobes. A repeat MRI now revealed bilateral Mesial Temporal Sclerosis. Clobazam was added to the carbamazepine regimen and seizures were incompletely controlled for another seven years.

The case was presented at a seizure conference. Because of bilateral MRI changes and a history of seizures from both left and right temporal lobes a decision to implant bilateral temporal depth electrodes was made (Figure 2a).

Following depth electrode implantation, it was found that the complex partial seizures originated exclusively from the right amygdala with spread over the right temporal lobe and later to the left temporal lobe (Figure 2b). Subsequently, a selective right amygdalohippocampectomy was performed. The patient has been seizure-free for the past two years on medication, although she still experiences auras.

\section{Case 3 (Patient \#6): Multiple intracranial tubers}

Patient \#6 was an 5-year-old, left-handed boy with Tuberous Sclerosis.

He was the product of a normal pregnancy and full term delivery. He was diagnosed to have Tuberous Sclerosis at three months-of-age, at which time he also started experiencing seizures. He had a rhabdomyoma, bilateral renal cyst, retinal hypopigmentation (no hamartomas), adenoma sebaceum, and shagreen spots. Moreover he exhibited global developmental delay and autistic spectrum disorder.

The seizures began at three months-of-age. They consisted of twitching on the right side of the face, drooling, and shaking of the right side of the body. Each of these episodes lasted 30-60 seconds. He was initially investigated in another epilepsy center 


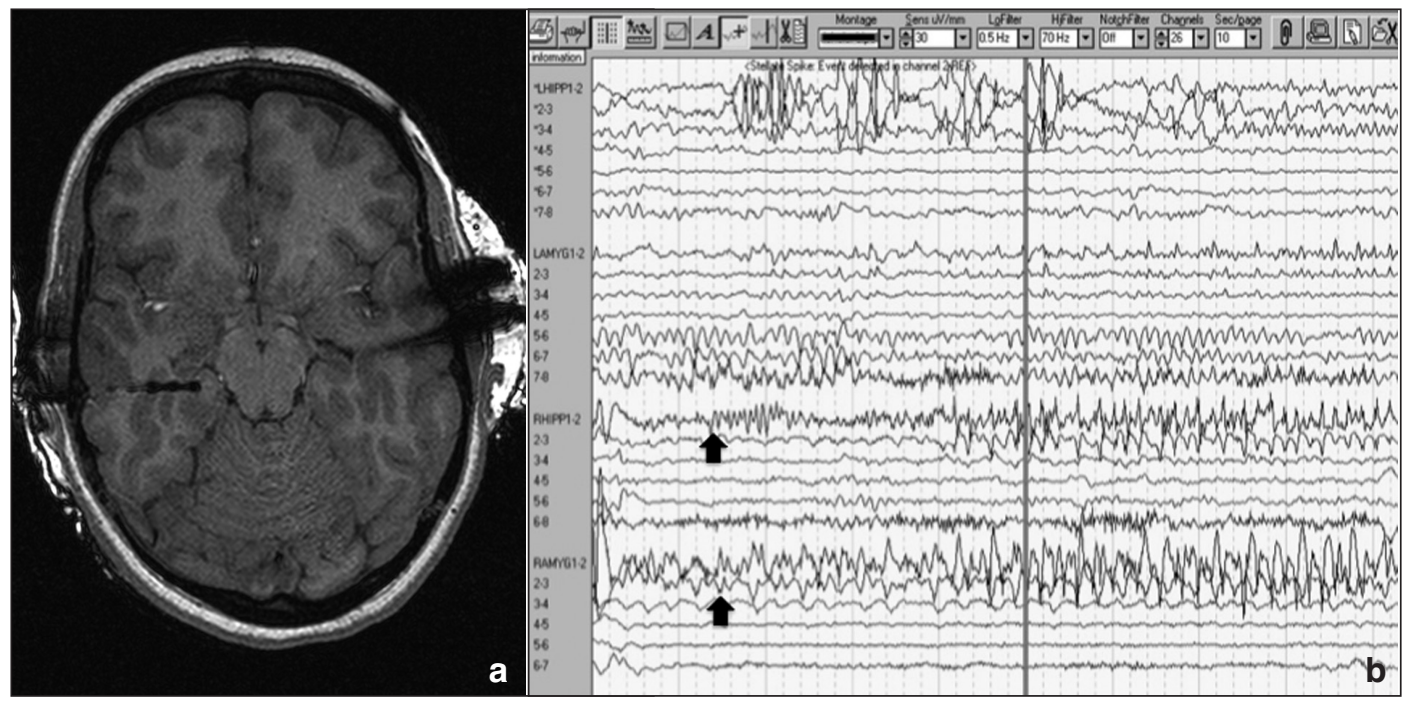

Figure 2: (Patient \#12): Bitemporal seizures. a) Magnetic resonance imaging showing implanted bitemporal depth electrodes. b) Depth electrode electroencephalogram showing seizure origin (arrows) from the right temporal lobe (amygdala and hippocampus).

and was treated with carbamazepine. Despite therapeutic intervention, he continued to have several seizures per day and night. According to records from the original treating hospital, he was treated with multiple medications including carbamazepine, vigabatrin, clobazam, valproic acid, and topiramate and not considered for epilepsy surgery in view of the presence of multiple tubers.

At the age of four years, he was referred to our center for a second opinion regarding epilepsy surgery having been refused surgery elsewhere. An MRI brain showed multiple tubers, including in the left sylvian fissure, left mesiofrontal, left frontal pole, right temporal lobe, and right frontal pole. The largest tuber was in left perisylvian region. Long-term video EEG recorded several stereotypical frontal lobe seizures. The seizure onset was in the left hemisphere with rapid secondary generalization although it was unclear from which tuber the seizure originated.

The patient had bilateral multiple depth electrodes implanted in the frontal and temporal lobes adjacent to the tubers (Figure 3a). A total of thirty-two seizures were recorded. All showed seizure onset from the left suprasylvian tuber with spread to the left frontal lobe, left SMA cortex, left frontal pole and right mesial frontal region (Figure 3b). The patient underwent a left suprasylvian fronto-central tuber resection and has been seizurefree for the past two years.

\section{Discussion}

Victor Horsley (1886) and Wilder Penfield (1930) pioneered the use of epilepsy surgery in adult patients ${ }^{11,12}$. Pediatric
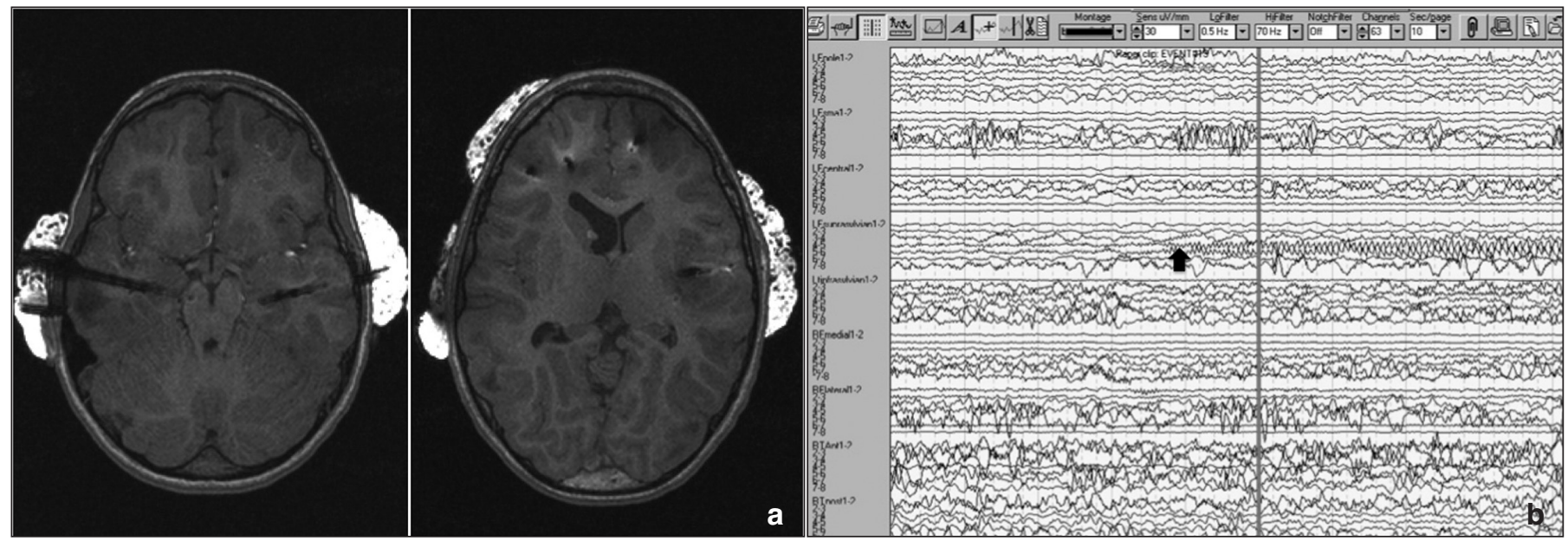

Figure 3: (Patient \#6): Tuberous Sclerosis and seizures. a) Magnetic resonance imaging showing implanted multifocal depth electrodes and multiple tubers in both hemisphere. b) Depth electrode electroencephalogram showing seizure origin (arrow) from the left suprasylvian tuber. 
epilepsy surgery was introduced in 1975 when Davidson and Falconer demonstrated that surgery could alter temporal lobe epilepsy ${ }^{13}$. Since then several studies have shown that pediatric epilepsy surgery provides gratifying outcome $e^{1,2,5,6,14}$. Still, the optimal criteria for selection are debated in the epilepsy community as epilepsy surgery in children is not simply an extension of treatment of adults. Heterogeneous causes of epilepsy, developmental progress, and capacity for plasticity of the brain as well as fears about surgical outcome makes pediatric epilepsy population unique from adults.

Depth electrode recording was first introduced in 1974 by Talairach and colleagues ${ }^{15}$ and have been studied for their accuracy, safety, and success rate in determining the location of a single epileptic zone that has proven difficult to identify by other non-invasive approaches ${ }^{9,16-20}$. However, few studies have reported the use of depth electrodes in the pediatric population 21-23. In our center, we have successfully used depth electrodes for more than ten years to precisely localize the epileptogenic zones and have performed their surgical removal without major complications. Importantly, the long-term results of this procedure have been safe and excellent for all patients. Patients previously considered inoperable have had successful epilepsy surgery following depth electrode implantation and recording.

In our study we found that $71 \%(10 / 14)$ had extratemporal lesions compared to $29 \%$ (4/14) temporal lesion which is consistent with previous studies which show that extra-temporal lesions comprise a major percentage of pediatric epilepsy patients $^{24,25}$. In terms of outcome, adult studies ${ }^{17,26}$ and some pediatric studies ${ }^{27,28}$ including our past series ${ }^{5}$ have shown that compared to temporal resection, with extra temporal resection fewer patients are rendered seizure free. However, our current study and others ${ }^{29,30}$ have shown excellent seizure reduction even with extra-temporal resection, likely because of the use of carefully coordinated invasive monitoring.

The pathological findings in surgical material from children with refractory epilepsy are different from those of adult patients. In pediatric epilepsy the most common pathology found was focal cortical dysplasia (FCD) ${ }^{31}$. In our group $35 \%$ had FCD which is a slightly higher percentage than in previous studie, ${ }^{32,33}$ likely because FCD are extremely difficult to detect with imaging techniques ${ }^{34}$ and non invasive techniques. Unlike adult studies $^{17}$, mesial temporal sclerosis is far less common in the pediatric population. In our study and other pediatric epilepsy studies, ${ }^{31}$ mesial temporal sclerosis was found in $10-15 \%$ of patients.

In Case $1 \mathrm{MRI}$, surface long-term video EEG monitoring, and the clinical profile yielded discordant data. It was unclear if seizures were of frontal or temporal onset. When depth electrodes were placed in the right fronto-temporal region, it was revealed that the epileptic zone was in the hippocampus and amygdala with spread occurring ipsilaterally to the frontal lobe. Previous studies in primates have shown that the temporal lobe is extensively connected with the orbitofrontal and medial prefrontal cortex ${ }^{35-37}$ and this connection has been demonstrated physiologically in humans ${ }^{36}$. Therefore, it was not surprising when the surface EEG recording for this patient showed a right frontal discharge while the clinical seizures suggested frontal lobe seizure semiology. Once we were able to successfully recognize the seizure generators in the hippocampus and amygdala and remove them via a selective amygdalo- hippocampectomy, the patient became seizure free while leaving the frontal lobe intact.

For Case \#2, bilateral independent epileptiform abnormalities involving both temporal lobes on scalp EEG have been observed in about $30 \%$ of temporal lobe epilepsy patients ${ }^{38-40}$, often making it challenging to localize the epileptogenic zone and with poor surgical outcome. However, approximately $20 \%$ of seizures rapidly spread to the contralateral hippocampus through the hippocampal commissure or frontal limbic pathways ${ }^{41,42}$. In Case 2, imaging results showed bilateral MTS, and the clinical seizures and surface EEG recordings did not conclusively identify the side of origin and the epilepsy surgery was delayed. With the use of depth electrodes we were able to localize the ictal zone and correct side and excise it with excellent surgical results following a selective amygdalohippocampectomy. A previously inoperable patient became operable with good results.

Epileptic seizures are very common in patients suffering from Tuberous Sclerosis and $50 \%$ of these seizures become intractable. Identification of the epileptogenic zone is challenging given the potentially multiple epileptogenic lesions visible on MRI ${ }^{14,43-45}$. Children (such as our Case 3) who present with multiple tubers may become refractory to multiple medications. Surface electrodes could not identify the tuber responsible for seizures and he was refused epilepsy surgery. Depth electrodes identified the candidate tuber with excellent results in a patient also previously considered inoperable.

The advantages of using depth electrode over scalp EEG monitoring has long been described ${ }^{7,8}$. Over the past decade, various intracranial recording techniques have been used to localize the epileptic origin. Some centers have relied on the use of epidural electrodes to study wide cortical regions in an attempt to localize, or more often lateralize, seizures ${ }^{46}$. Similarly, foramen ovale electrodes have been used to localize mesial temporal discharges because they may be placed extraoperatively and lie outside the dura ${ }^{47}$. We have previously used subdural EEG recording in our patients requiring invasive monitoring. However, a major disadvantage of all of these intracranial recording modalities, aside from a craniotomy and complications such as infection, aseptic meningitis, inflammation, and hemorrhage, is their ineffectiveness to specifically localize the epileptogenic zone and in some cases providing false lateralization ${ }^{48}$. Shift in plate location remains a major drawback. According to the most recent study by Placantonakis, the use of depth electrodes represents the most accurate way of localizing epileptic origin ${ }^{49}$. We have been implanting depth electrodes for ten years with the help of an experienced team and we have experienced only rare complications during the post-implantation stage ${ }^{10}$. Patients are up and about following implantation with no morbidity. Moreover, patients achieve complete seizure freedom after accurate localization and resection of the epileptogenic zone.

One of the most complex issues in epilepsy surgery is accurately targeting the foci and removing the zone of interest while producing a minimal amount of additional neurological damage. Depth electrodes have a very focal and limited recording potential, so a well-established hypothesis and identification of the epileptic zone is needed prior to implantation. We recently have started using stereotactic guided MRI for depth electrode placement. It has been shown that MRI- 
guided stereotactic implantation may substantially reduce the risk of complication ${ }^{50}$.

Although, depth electrodes can be used to functionally map brain function, we rarely did this in our young patient group due to high resistance of brain, unpredictable results, and lack of normative data as in adult patients.

\section{Conclusion}

We retrospectively evaluated a heterogeneous pediatric cohort with medically intractable epilepsy treated successfully following the use of depth electrodes to identify the epileptic zone. Many of these patients were previously considered inoperable based on surface EEG and MRI. New data following depth implantation allowed us to proceed with epilepsy surgery in these patients. The clinical outcomes achieved, including complete resolution of seizures with few post-operative complications, indicate that depth electrodes can provide additional information towards accurately localizing the epileptogenic zone and can be safely used in the pediatric population. Many patients considered inoperable may now become candidates for epilepsy surgery.

\section{REFERENCES}

1. Duchowny M. Epilepsy surgery in children. Curr Opin Neurol. 1995;8(2):112-6.

2. Duchowny M. Pediatric epilepsy surgery: the widening spectrum of surgical candidacy. Epileptic Disord. 1999;1(3):143-51.

3. Duchowny MS. Surgery for intractable epilepsy: issues and outcome. Pediatrics. 1989;84(5):886-94.

4. Rosenow F, Luders H. Presurgical evaluation of epilepsy. Brain. 2001;124(Pt 9): 1683-700.

5. Sinclair DB, Aronyk KE, Snyder TJ, et al. Pediatric epilepsy surgery at the University of Alberta: 1988-2000. Pediatr Neurol. 2003;29(4):302-11.

6. Wyllie E, Comair YG, Kotagal P, Raja S, Ruggieri P. Epilepsy surgery in infants. Epilepsia. 1996;37(7):625-37.

7. Brekelmans GJ, van Emde Boas W, Velis DN, Lopes da Silva FH, van Rijen PC, van Veelen CW. Comparison of combined versus subdural or intracerebral electrodes alone in presurgical focus localization. Epilepsia. 1998;39(12):1290-301.

8. Cohen-Gadol AA, Wilhelmi BG, Collignon F, et al. Long-term outcome of epilepsy surgery among 399 patients with nonlesional seizure foci including mesial temporal lobe sclerosis. J Neurosurg. 2006;104(4):513-24.

9. Engel J. Surgical treatment of the epilepsies. New York: Raven Press; 1987.

10. Jacob FD, Wheatley MB, Sinclair DB. Acute neurogenic pulmonary edema after depth electrode placement for epilepsy surgery. Can J Neurol Sci. 2010;37(6):885-7.

11. Horsley V. Brain surgery. Br Med J. 1886;1886(2):670-5.

12. Penfield W. The radical treatment of traumatic epilepsy and its rationale. Can Med Assoc J. 1930;23(2):189-97.

13. Davidson S, Falconer MA. Outcome of surgery in 40 children with temporal-lobe epilepsy. Lancet. 1975;1(7919):1260-3.

14. Koh S, Jayakar P, Dunoyer C, et al. Epilepsy surgery in children with tuberous sclerosis complex: presurgical evaluation and outcome. Epilepsia. 2000;41(9):1206-13.

15. Talairach J, Bancaud J, Szikla G, Bonis A, Geier S, Vedrenne C. [New approach to the neurosurgery of epilepsy. Stereotaxic methodology and therapeutic results. 1. Introduction and history]. Neurochirurgie. 1974;20 Suppl 1:1-240.

16. Engel J. Surgical treatment of the epilepsies. 2nd ed. New York: Raven Press; 1993.

17. Engel J, Jr. Surgery for seizures. N Engl J Med. 1996;334(10): 647-52.

18. Engel J, Jr. Research on the human brain in an epilepsy surgery setting. Epilepsy Res. 1998;32(1-2):1-11.
19. Spencer SS, Spencer DD, Williamson PD, Mattson R. Combined depth and subdural electrode investigation in uncontrolled epilepsy. Neurology. 1990;40(1):74-9.

20. Williamson A, Spencer SS, Spencer DD. Depth electrode studies and intracellular dentate granule cell recordings in temporal lobe epilepsy. Ann Neurol. 1995;38(5):778-87.

21. Levitt MR, Ojemann JG, Kuratani J. Insular epilepsy masquerading as multifocal cortical epilepsy as proven by depth electrode. J Neurosurg Pediatr. 2010;5(4):365-7.

22. Lopez HE, Fohlen M, Lelouch-Tubiana A, et al. Heterotopia associated with hippocampal sclerosis: an under-recognized cause of early onset epilepsy in children operated on for temporal lobe epilepsy. Neuropediatrics. 2010;41(4):167-75.

23. Privitera MD, Yeh HS, Blisard K, Sanchez N. Detection of epileptogenic focal cortical dysplasia by depth, not subdural electrodes. Neurosurg Rev. 2000;23(1):49-51.

24. Wyllie E, Comair YG, Kotagal P, Bulacio J, Bingaman W, Ruggieri P. Seizure outcome after epilepsy surgery in children and adolescents. Ann Neurol. 1998;44(5):740-8.

25. Diehl B, Wyllie E, Rothner AD, Bingaman W. Worsening seizures after surgery for focal epilepsy due to emergence of primary generalized epilepsy. Neurology. 1998;51(4):1178-80.

26. Spencer SS. Long-term outcome after epilepsy surgery. Epilepsia. 1996;37(9):807-13.

27. Kan P, Van Orman C, Kestle JR. Outcomes after surgery for focal epilepsy in children. Childs Nerv Syst. 2008;24(5):587-91.

28. Van Oijen M, De Waal H, Van Rijen PC, Jennekens-Schinkel A, van Huffelen AC, Van Nieuwenhuizen O. Resective epilepsy surgery in childhood: the Dutch experience 1992-2002. Eur J Paediatr Neurol. 2006;10(3):114-23.

29. Cukiert A, Buratini JA, Machado E, et al. Results of surgery in patients with refractory extratemporal epilepsy with normal or nonlocalizing magnetic resonance findings investigated with subdural grids. Epilepsia. 2001;42(7):889-94.

30. Wetjen NM, Marsh WR, Meyer FB, et al. Intracranial electroencephalography seizure onset patterns and surgical outcomes in nonlesional extratemporal epilepsy. J Neurosurg. 2009;110(6):1147-52.

31. Mohamed A, Wyllie E, Ruggieri P, et al. Temporal lobe epilepsy due to hippocampal sclerosis in pediatric candidates for epilepsy surgery. Neurology. 2001;56(12):1643-9.

32. Brodtkorb E, Nilsen G, Smevik O, Rinck PA. Epilepsy and anomalies of neuronal migration: MRI and clinical aspects. Acta Neurol Scand. 1992;86(1):24-32.

33. Polkey CE. Cortical dysplasia: resective surgery in children. In: Guerrini R, Andermann F, Canapicchi R, editors. Dysplasias of cerebral cortex and epilepsy. Philadelphia: Lippincot-Raven; 1996. p. $740-8$

34. Guerrini R, Dobyns WB, Barkovich AJ. Abnormal development of the human cerebral cortex: genetics, functional consequences and treatment options. Trends Neurosci. 2008;31(3):154-62.

35. Carmichael ST, Price JL. Architectonic subdivision of the orbital and medial prefrontal cortex in the macaque monkey. J Comp Neurol. 1994;346(3):366-402.

36. Kendrick JF, Gibbs FA. Interrelations of mesial temporal and orbital frontal areas of man revealed by strychnine spikes. AMA Arch Neurol Psychiatry. 1958;79(5):518-24.

37. Kondo H, Saleem KS, Price JL. Differential connections of the temporal pole with the orbital and medial prefrontal networks in macaque monkeys. J Comp Neurol. 2003;465(4):499-523.

38. Gastaut $H$, Naquet R, Vigouroux R, Roger A, Badier M. [Electrographic studies in man and in animal in so-called psychomotor epilepsy]. Rev Neurol (Paris). 1953;88(5):310-54.

39. Rovit RL, Gloor P, Rasmussen T. Sphenoidal electrodes in the electrographic study of patients with temporal lobe epilepsy. An evaluation. J Neurosurg. 1961;18:151-8.

40. So N, Gloor P, Quesney LF, Jones-Gotman M, Olivier A, Andermann F. Depth electrode investigations in patients with bitemporal epileptiform abnormalities. Ann Neurol. 1989;25(5): 423-31.

41. Gloor P, Salanova V, Olivier A, Quesney LF. The human dorsal hippocampal commissure. An anatomically identifiable and functional pathway. Brain. 1993;116 (Pt 5):1249-73. 
42. Lieb JP, Dasheiff RM, Engel J, Jr. Role of the frontal lobes in the propagation of mesial temporal lobe seizures. Epilepsia. 1991;32(6):822-37.

43. Avellino AM, Berger MS, Rostomily RC, Shaw CM, Ojemann GA. Surgical management and seizure outcome in patients with tuberous sclerosis. J Neurosurg. 1997;87(3):391-6.

44. Baumgartner JE, Wheless JW, Kulkarni S, et al. On the surgical treatment of refractory epilepsy in tuberous sclerosis complex. Pediatr Neurosurg. 1997;27(6):311-8.

45. Bebin EM, Kelly PJ, Gomez MR. Surgical treatment for epilepsy in cerebral tuberous sclerosis. Epilepsia. 1993;34(4):651-7.

46. Awad IA, Assirati JA, Jr., Burgess R, Barnett GH, Luders H. A new class of electrodes of 'intermediate invasiveness': preliminary experience with epidural pegs and foramen ovale electrodes in the mapping of seizure foci. Neurol Res. 1991;13(3):177-83.
47. Wieser HG, Siegel AM. Analysis of foramen ovale electroderecorded seizures and correlation with outcome following amygdalohippocampectomy. Epilepsia. 1991;32(6):838-50.

48. Alsaadi TM, Laxer KD, Barbaro NM, Marks WJ, Jr., Garcia PA. False lateralization by subdural electrodes in two patients with temporal lobe epilepsy. Neurology. 2001;57(3):532-4.

49. Placantonakis DG, Shariff S, Lafaille F, et al. Bilateral intracranial electrodes for lateralizing intractable epilepsy: efficacy, risk, and outcome. Neurosurgery. 2010;66(2):274-83.

50. Ross DA, Brunberg JA, Drury I, Henry TR. Intracerebral depth electrode monitoring in partial epilepsy: the morbidity and efficacy of placement using magnetic resonance imageguided stereotactic surgery. Neurosurgery. 1996;39(2):327-33; discussion 33-4. 